\section{Diversidade sexual na escola: estudo qualitativo com estudantes do Ensino Médio do Município do Rio de Janeiro, Brasil}

\author{
Sexual diversity in schools: a qualitative study \\ with high school students in the Municipality \\ of Rio de Janeiro, Brazil
}

Diversidad sexual en la escuela: estudio

cualitativo con estudiantes de la enseñanza media del Municipio de Río de Janeiro, Brasil
Thenessi Freitas Matta 1 Stella Regina Taquette 2 Luciana Maria Borges da Matta Souza 2,3 Claudia Leite de Moraes 3,4

doi: 10.1590/0102-311X00330820

\section{Resumo}

A LGBTfobia se configura como contexto de vulnerabilidade à saúde das pessoas cuja sexualidade é diversa do padrão heteronormativo, denominadas minorias sexuais, principalmente na adolescência, período de definição das identidades sexuais. $O$ objetivo deste estudo foi analisar como estudantes do Ensino Médio percebem seus pares das minorias sexuais e como entendem a atitude da escola e educadores frente à diversidade sexual. O método utilizado foi qualitativo por meio de 13 grupos focais com 132 estudantes de ambos os sexos, de escolas públicas e privadas de Município do Rio de Janeiro, Brasil. A análise dos dados foi realizada com apoio do software webQDA, em uma abordagem de base compreensiva, e os dados classificados em duas categorias. $\mathrm{Na}$ primeira, denominada "os estudantes e a diversidade sexual", os participantes percebem a diversidade sexual como normal, pois é comum e se apresenta frequentemente na idade deles. Contudo, confirmaram atitudes homofóbicas contra aqueles cujo comportamento de gênero não está de acordo com o esperado para seu sexo biológico. Na segunda categoria, "a escola e a diversidade sexual", os estudantes reconhecem a adoção de medidas discriminatórias contra casais homoafetivos por parte da coordenação escolar e a ausência do tema diversidade sexual nas atividades educativas. Os resultados indicam que as políticas de educação sexual são insuficientes para a garantia dos direitos humanos das minorias sexuais, o que representa maior vulnerabilidade à saúde desse estrato populacional.

Homofobia; Sexualidade; Adolescente; Estudantes; Pesquisa Qualitativa

\author{
Correspondência \\ T. F. Matta \\ Programa de Pós-graduação em Bioética, Ética Aplicada e Saúde \\ Coletiva, Universidade do Estado do Rio de Janeiro. \\ Boulevard Vinte e Oito de Setembro 109, Rio de Janeiro, RJ \\ 20551-030, Brasil. \\ thenessi@gmail.com \\ 1 Programa de Pós-graduação em Bioética, Ética Aplicada e \\ Saúde Coletiva, Universidade do Estado do Rio de Janeiro, \\ Rio de Janeiro, Brasil. \\ 2 Faculdades de Ciências Médicas, Universidade do Estado do \\ Rio de Janeiro, Rio de Janeiro, Brasil. \\ 3 Faculdade de Medicina, Universidade Estácio de Sá, \\ Rio de Janeiro, Brasil. \\ 4 Instituto de Medicina Social, Universidade do Estado do \\ Rio de Janeiro, Rio de Janeiro, Brasil.
}




\section{Introdução}

A adolescência, etapa da vida compreendida entre 10 e 19 anos segundo a Organização Mundial da Saúde (OMS), é um período marcado pela conquista de maior autonomia e independência em relação à família e de experimentação de novos comportamentos, sendo comum a ocorrência das primeiras relações amorosas e experiências sexuais com envolvimento genital, homo ou heterossexuais 1 .

A prática sexual transcende o biológico, visto que envolve aspectos psicológicos, culturais e sociais 2 . $\mathrm{Na}$ fase da adolescência vão sendo definidas a identidade de gênero e a orientação sexual dos indivíduos. Aqueles que se percebem diferentes do padrão heteronormativo da sociedade via de regra sentem desconforto, estranheza e inquietações. Por vezes, estas sensações, associadas à discriminação que sofrem, ocasionam problemas de saúde 3 .

Adolescentes que têm desejos eróticos por pessoas do mesmo sexo ou que transgridam as normas de gênero e sexualidade, ou seja, a heteronormatividade, frequentemente são vítimas de preconceitos 4 . São atitudes hostis e irracionais que caracterizam a homofobia, segundo Borillo 5 , contra pessoas com orientação sexual diversa do considerado "normal" na sociedade. Contudo, a discriminação não se restringe apenas aos que têm orientação sexual diversa, mas também àqueles com identidade e expressões de gênero não hegemônicas, sendo o termo LGBTfobia mais adequado, por abarcar todos os pertencentes às minorias sexuais 6 .

A LGBTfobia enraizada na sociedade gera diversos prejuízos para as pessoas que fogem à heteronormatividade. Devido a isso, adolescentes das minorias sexuais quase sempre se engajam menos em comportamentos de autocuidado à saúde, sofrem mais violência e não recebem atendimento, nos serviços de saúde, que leve em conta sua diversidade 3. Muitos lutam contra seus desejos tendo como consequência distúrbios psicológicos, sentimentos de culpa, ansiedade, vergonha e depressão. Ademais, existe o estereótipo de que essas pessoas são incapazes de ter uma vida afetiva plenamente desenvolvida, nem família, nem filhos, o que pode levar a um sentimento de solidão insuportável que culmina no suicídio 7 . Tanto a depressão, como o comportamento suicida são mais frequentes entre homossexuais do que em heterossexuais $8,9,10$.

A escola é o ambiente social em que os adolescentes e jovens permanecem grande parte de suas vidas sendo, portanto, um espaço fundamental para o seu bem-estar. Além disso, é um lugar privilegiado para a formação de cidadãos e para o ensinamento do respeito aos direitos humanos. Entretanto, sabe-se que este ambiente é heteronormatizador, controlador e disciplinador da sexualidade 11. Muitas vezes, o que se vê é uma escola que se mostra hostil àqueles que fogem ao padrão e são tidos como diferentes. Neste contexto é comum adolescentes homossexuais serem vítimas de bullying LGBTfóbico e sofrerem reprimendas de seus superiores. Essa discriminação tem grande impacto na autoestima e somado à homofobia internalizada pode provocar abandono da escola, com consequente prejuízo à vida futura 12 .

Esta pesquisa teve como objetivo analisar como estudantes do Ensino Médio de escolas públicas e privadas percebem aqueles que têm sexualidade diversa do padrão heteronormativo e o entendimento que têm sobre a atitude dos educadores frente à diversidade sexual. Apesar de já haver algum conhecimento sobre o assunto no Brasil, verifica-se que investigações sobre o tema com abordagem qualitativa ainda são insuficientes e envolvem estabelecimentos públicos em sua maioria. Ao incluir escolas privadas, a presente investigação deu um passo além.

\section{Métodos}

Este artigo faz parte de pesquisa mais ampla sobre sexualidade e violência entre adolescentes, desenvolvida com abordagem mista, quanti e qualitativa, com estudantes do segundo ano do Ensino Médio, de ambos os sexos, em escolas públicas e privadas da IX Região Administrativa do Município do Rio de Janeiro, Brasil. A eleição deste público-alvo se deu pela maior probabilidade de já terem experiência sexual e ainda estarem na faixa etária da adolescência. A região foi escolhida por conveniência, pela integração com as escolas da área advindas de parcerias prévias. Os estabelecimentos escolares foram sorteados. 
O estudo apresentado neste artigo se refere à etapa qualitativa e a técnica escolhida foi a de grupo focal, que comporta a coleta de dados por meio das interações entre os indivíduos e é útil na compreensão do processo de construção de percepções, atitudes e representações sociais dos grupos humanos 13 .

Os dados foram coletados após contato e permissão dos estabelecimentos escolares e dos responsáveis, durante o ano letivo de 2016. A equipe de pesquisa reuniu-se com os estudantes das turmas disponibilizadas pela escola, explicou sobre o conteúdo da investigação, os temas a serem discutidos e os primeiros que concordavam em participar permaneciam na sala, no número máximo de 12 integrantes e mínimo de seis. Portanto, os grupos foram formados com pessoas que se conheciam. Alguns grupos foram compostos com estudantes de ambos os sexos e outros separados por sexo para ampliar a diversidade das discussões. Foi pactuado que a discussão não incluía a exposição das experiências pessoais dos participantes. Os cuidados necessários para garantir a participação equilibrada de todos os componentes foram tomados, por exemplo, quando havia polarização da discussão por algum integrante do grupo, impedindo a participação dos demais. Também foram feitas intervenções pontuais para o bom andamento das discussões, por exemplo, quando assuntos de natureza pessoal eram invocados no grupo.

Seguimos roteiro com questões relacionadas à sexualidade, gênero e orientação sexual, sobre como os alunos percebem aqueles que não se encaixam no padrão heterossexual e a atitude da escola e de educadores frente à diversidade sexual. Ao final de cada reunião foi aplicado questionário autopreenchível para coleta de dados sociodemográficos e de experiência sexual dos participantes. Cada grupo foi conduzido por dois profissionais, sendo um moderador e um observador. A duração média das reuniões foi de 60 minutos, sendo gravadas e posteriormente transcritas.

A equipe da pesquisa foi composta por profissionais de medicina, enfermagem, psicologia e serviço social, que se revezaram na condução e observação dos grupos. Não havia nenhum relacionamento prévio entre os pesquisadores e os pesquisados. As reuniões foram interrompidas após o $13^{\circ}$ grupo, em razão da repetição das informações, sem dados novos. O critério amostral, portanto, foi a saturação dos conteúdos. Houve garantia de equilíbrio entre o número de participantes de escolas públicas e privadas e de ambos os sexos.

A análise dos dados foi realizada com apoio do software webQDA (https://www.webqda.net/) 14 de acordo com princípios hermenêuticos-dialéticos, tendo como base teórica autores como Denzin \& Lincoln 15 e Minayo ${ }^{13}$. Foi desenvolvida pelos seguintes passos: leitura e releitura compreensiva dos dados com busca de similaridades e divergências; codificação dos relatos de acordo com o entendimento destes; identificação dos sentidos atribuídos pelos sujeitos às questões levantadas; diálogo comparativo com a literatura; e elaboração de síntese interpretativa.

Foi utilizado o termo "diversidade sexual" para caracterizar a expressão da sexualidade normal que não segue o padrão heteronormativo, tanto relacionada à orientação sexual como à manifestação de gênero, e o termo "minorias sexuais" para aqueles aderentes à diversidade sexual, comumente referidos como população de lésbicas, gays, bissexuais, transsexuais, transgêneros e travestis (LGBT). Já o termo "pessoas trans" foi referido àqueles que têm forte desagrado ou desconforto com o sexo atribuído ao nascimento e um desejo de ser tratado pelo sexo com o qual se identifica 16 .

\section{Aspectos éticos}

O estudo atende às normas éticas contidas na Resolução no 510/2016 do Conselho Nacional de Saúde e foi aprovado pelo Comitê de Ética em Pesquisa da Universidade do Estado do Rio de Janeiro em 18 de setembro de 2015 (CAAE no 48107514.2.0000.5282) e autorizado pela Secretaria Estadual de Educação do Rio de Janeiro. 


\section{Resultados e discussão}

Do total de 13 grupos focais, sete foram realizados em escolas públicas e seis em privadas, que abarcaram 132 estudantes, metade de cada segmento. As alunas eram maioria, 55\% do total. Cinco grupos foram compostos apenas com integrantes do sexo masculino, cinco do sexo feminino e três mistos. Relataram já ter experiências sexuais $64,4 \%$ dos entrevistados. Destes, somente $4,7 \%$ informaram ter sido com pessoas do mesmo sexo.

Os dados sociodemográficos comparados por sexo masculino ou feminino autorreferido evidenciaram que os rapazes são um pouco mais velhos e predominantemente de raça/cor negra ( $57 \%$ contra $42 \%$ no sexo feminino). Em relação à atividade sexual, foram constatados percentuais semelhantes de estudantes de ambos os sexos que já a praticavam ( $63 \%$ no sexo masculino e $65 \%$ no feminino). A experiência homossexual foi relatada por três alunas, enquanto apenas um aluno declarou esta posição, indicando uma frequência igualmente reduzida desse tipo de atividade (Tabela 1).

\section{Tabela 1}

Distribuição dos dados sociodemográficos por sexo. Município do Rio de Janeiro, Brasil, 2016.

\begin{tabular}{|c|c|c|c|c|}
\hline \multirow[t]{2}{*}{ Variável } & \multicolumn{2}{|c|}{ Feminino } & \multicolumn{2}{|c|}{ Masculino } \\
\hline & $\mathbf{n}$ & $\%$ & $\mathbf{n}$ & $\%$ \\
\hline \multicolumn{5}{|l|}{ Faixa etária (anos) } \\
\hline $15-17$ & 53 & 73 & 41 & 68 \\
\hline $18-21$ & 17 & 23 & 19 & 32 \\
\hline$>21$ & 1 & 2 & 0 & 0 \\
\hline Não informado & 1 & 2 & 0 & 0 \\
\hline Total & 72 & 100 & 60 & 100 \\
\hline \multicolumn{5}{|l|}{ Raça/Cor } \\
\hline Branca & 37 & 51 & 24 & 40 \\
\hline Parda e preta & 30 & 42 & 34 & 57 \\
\hline Indígena, amarela e não informada & 5 & 7 & 2 & 3 \\
\hline Total & 72 & 100 & 60 & 100 \\
\hline \multicolumn{5}{|l|}{ Sexarca } \\
\hline Sim & 47 & 65 & 38 & 63 \\
\hline Não & 25 & 35 & 22 & 37 \\
\hline Total & 72 & 100 & 60 & 100 \\
\hline \multicolumn{5}{|l|}{ Idade da sexarca } \\
\hline$\leq 14$ & 14 & 30 & 13 & 34 \\
\hline $15-17$ & 31 & 66 & 25 & 66 \\
\hline$\geq 18$ & 2 & 4 & 0 & 0 \\
\hline Total & 47 & 100 & 38 & 100 \\
\hline \multicolumn{5}{|l|}{ Experiência homossexual } \\
\hline Sim & 3 & 7 & 1 & 2 \\
\hline Não & 44 & 93 & 37 & 98 \\
\hline Total & 47 & 100 & 38 & 100 \\
\hline \multicolumn{5}{|l|}{ Renda familiar (salários mínimos) } \\
\hline$\leq 3$ & 29 & 40 & 28 & 46 \\
\hline$>3$ & 36 & 50 & 24 & 40 \\
\hline Não informado & 7 & 10 & 8 & 14 \\
\hline Total & 72 & 100 & 60 & 100 \\
\hline Total geral & 72 & 100 & 60 & 100 \\
\hline
\end{tabular}


Em relação ao tipo de escola, nas privadas houve predomínio de alunos mais novos, entre 15 e 17 anos e da raça/cor branca em $70 \%$ deles, sendo o índice de $23 \%$ nas públicas. A maior média de idade dos alunos na escola pública corresponde a índices mais elevados de repetência e atraso escolar. Os que já tinham experiência sexual foram mais numerosos nas escolas públicas do que nas privadas, sendo as taxas de 72\% e 56\%, respectivamente. Quanto à experiência homossexual, não houve diferença entre o número de adolescentes que relataram a situação entre as escolas públicas e privadas, dois em cada tipo de escola. Os estudantes das escolas privadas apresentavam pais com renda bem mais elevada do que os alunos das escolas públicas (Tabela 2).

$\mathrm{Na}$ análise dos dados textuais, não observamos diferenças relevantes entre as narrativas dos alunos das escolas públicas e das privadas. Por este motivo, estes foram agrupados e classificados conjuntamente em duas categorias, tendo em vista os objetivos do estudo: (1) os estudantes e diversidade sexual, que se refere à percepção dos participantes do grupo sobre seus pares de minorias sexuais; e (2) a escola e a diversidade sexual, que diz respeito à percepção dos participantes sobre como os professores e coordenação pedagógica lidam com a diversidade sexual na escola.

Tabela 2

Distribuição dos dados sociodemográficos por tipo de escola. Município do Rio de Janeiro, Brasil, 2016.

\begin{tabular}{|c|c|c|c|c|}
\hline \multirow[t]{2}{*}{ Variável } & \multicolumn{2}{|c|}{ Escolas públicas } & \multicolumn{2}{|c|}{ Escolas particulares } \\
\hline & $\mathbf{n}$ & $\%$ & $\mathbf{n}$ & $\%$ \\
\hline \multicolumn{5}{|l|}{ Faixa etária (anos) } \\
\hline $15-17$ & 36 & 54 & 58 & 88 \\
\hline $18-21$ & 29 & 44 & 7 & 10 \\
\hline$>21$ & 1 & 2 & 0 & 0 \\
\hline Não informado & 0 & 0 & 1 & 2 \\
\hline Total & 66 & 100 & 66 & 100 \\
\hline \multicolumn{5}{|l|}{ Raça/Cor } \\
\hline Branca & 15 & 23 & 46 & 70 \\
\hline Parda e preta & 47 & 71 & 17 & 26 \\
\hline Indígena, amarela e não informada & 4 & 6 & 3 & 4 \\
\hline Total & 66 & 100 & 66 & 100 \\
\hline \multicolumn{5}{|l|}{ Sexarca } \\
\hline Sim & 48 & 72 & 37 & 56 \\
\hline Não & 18 & 28 & 29 & 44 \\
\hline Total & 66 & 100 & 66 & 100 \\
\hline \multicolumn{5}{|l|}{ Idade da sexarca } \\
\hline$\leq 14$ & 16 & 33 & 11 & 30 \\
\hline $15-17$ & 31 & 65 & 25 & 68 \\
\hline$\geq 18$ & 1 & 2 & 1 & 2 \\
\hline Total & 48 & 100 & 37 & 100 \\
\hline \multicolumn{5}{|l|}{ Experiência homossexual } \\
\hline $\operatorname{Sim}$ & 2 & 4 & 2 & 5 \\
\hline Não & 46 & 96 & 35 & 95 \\
\hline Total & 48 & 100 & 37 & 100 \\
\hline \multicolumn{5}{|l|}{ Renda familiar (salários mínimos) } \\
\hline$\leq 3$ & 42 & 63 & 15 & 23 \\
\hline$>3$ & 18 & 27 & 42 & 64 \\
\hline Não informado & 6 & 10 & 9 & 13 \\
\hline Total & 66 & 100 & 66 & 100 \\
\hline Total geral & 66 & 100 & 66 & 100 \\
\hline
\end{tabular}


As narrativas dos participantes indicam que adolescentes das minorias sexuais estão mais visíveis e sofrendo menos rejeição pelos pares nas escolas. De modo geral, na percepção deles, na escola, o índice de rejeição é menor do que no meio social externo. Além disso, a quantidade de estudantes manifestamente não heterossexual é grande, inclusive pela circunstância dessa etapa da vida que estão passando ser de descobertas e de definição da identidade sexual. $O$ fato de ser comum faz com que todos se acostumem e deixem de sentir a diversidade sexual como estranha, diferente, diminuindo o preconceito. Afirmam que hoje a homossexualidade, a transexualidade e outras expressões da sexualidade e do gênero são mais presentes nos veículos de comunicação, especialmente na Internet, o que também contribui para uma maior receptividade.

"É muita convivência, a gente se acostuma" (aluna, G1).

"Eu tenho vários amigos gays e lésbicas, não é uma nem duas, são vários" (aluna, G4).

"Hoje em dia é normal" (aluno, G3).

Os participantes argumentaram que na atualidade a escola amplia a visão dos jovens, principalmente com o estudo de determinadas matérias em que há mais diálogo com os alunos. Antes, na geração dos pais e dos avós, havia mais discriminação.

"...A maioria da gente quando entra aqui é tipo 'ah, sou contra isso, sou contra aquilo'. Só que aqui a gente meio que abre a mente! A gente começa a ver as paradas diferente" (aluna, G11).

"Hoje em dia tem muita informação pra poder abrir nossa cabeça" (aluna, G9).

Contudo, essa aceitação da diversidade sexual não é unânime nem incondicional e ocorre por motivos diversos. Para alguns, mesmo que a homossexualidade não seja uma coisa "normal", as pessoas não heterossexuais devem ser respeitadas. A pesquisa Diversidade Sexual e Homofobia no Brasil 17, realizada em âmbito nacional, evidenciou que as taxas de homofobia tendem a cair na medida em que as pessoas têm contato com o público LGBT.

As estudantes do sexo feminino demonstram mais predisposição a aceitar tipos diversos de comportamento sexual não heteronormativo do que os rapazes. Elas também se mostraram mais participantes e eloquentes na discussão do tema. Os rapazes foram mais econômicos nas palavras, parecendo ter receio de confessar conhecimento sobre assunto e, por isso, serem considerados homossexuais ou simpatizantes. Entre eles, houve afirmação que poderia levar ao entendimento da homossexualidade ser contagiosa:

"Pode me dar um cigarro? E ele pegar e botar o cigarro na boca. Pra mim fumar, eu não aceito (...) Agora, se ele tirar dentro de um maço e me dar, é uma coisa" (aluno, G6).

Foram frequentes as narrativas de que causa desconforto ver casais gays se abraçando ou se beijando e afirmaram que cada um pode fazer o que quiser, mas somente na intimidade. Houve quem dissesse que também se sente incomodado ao ver carícias em público de casais heterossexuais, que isso deve ser feito somente em ambiente privado, "entre quatro paredes". Porém, estas falas surgiram apenas como justificativa da rejeição de demonstração de afeto em público de homossexuais, talvez para não se mostrarem preconceituosos.

A menor aceitação da diversidade sexual por parte dos rapazes ficou evidente ao se referirem aos integrantes das minorias sexuais que se expõem da forma como se sentem. Nossos interlocutores, ao mencionarem os homens gays, demostraram tolerar apenas aqueles que agem de acordo com o padrão tradicional de masculinidade. Qualquer desvio desta conduta é rechaçado por eles. Rapazes que usam roupas ditas femininas são discriminados. $\mathrm{Na}$ fala dos alunos, a violência contra homossexuais mais frequentemente se justifica nestes casos.

"Tem que vir normal. Tem gente que já vem de calça apertada" (aluno, G2).

"Um homossexual que anda na rua assim, vai ser agredido" (aluno, G2).

A não rejeição ao público das minorias sexuais é, então, seletiva, acontecendo quando o indivíduo se comporta de acordo com o esperado para o sexo que pertence. Portanto, a discriminação ainda existe.

A menor aceitação por parte dos estudantes, daqueles que exteriorizam a homossexualidade pelos gestos ou vestuário se configura numa violência, pois obriga o indivíduo a velar sua orientação sexual. Essa invisibilização da diversidade sexual é um mecanismo de legitimação da homofobia 18. Rondini et al. 19, em estudo com 2.159 alunos do Ensino Médio, evidenciaram o que denominaram de homofobia cordial, quando o indivíduo aceita um amigo ou amiga gay desde que esses não apresentem 
trejeitos do outro sexo. Ou seja, a homossexualidade é admitida desde que não apareça, que o homossexual não saia do "armário". Essa lógica explica por que pessoas trans são mais vulneráveis à violência.

Magnavita 20 aponta que a seletividade na discriminação também acontece entre os gays. Só é possível ser homossexual e não ser discriminado, inclusive por seus pares, se seguir a cartilha que apresenta modelo aceitável de comportamento, pautado pela misoginia e pelo machismo. Isso é evidente com pessoas trans que, para serem aceitas, têm que percorrer um longo caminho 21,22, reconhecido por nossos interlocutores como um processo muito difícil e sofrido.

A homofobia maior entre os homens, relatada pelos alunos, é corroborada por outros estudos. Homens jovens rejeitam mais homossexuais e transexuais do que mulheres jovens e até do que homens mais velhos. Este comportamento representa a afirmação da identidade masculina nessa fase da vida. A homofobia não se dirige somente às pessoas das minorias sexuais, mas também para aqueles que não se comportam de acordo com o modelo hegemônico de seu respectivo gênero. Segundo estudo realizado no México 23, os indivíduos mais homofóbicos são os homens, os mais envolvidos com religião, os que não têm amigos homossexuais e os com posição política conservadora. Nesta mesma direção, pesquisadores 24 encontraram em investigação com 30 mil alunos de seis países da América Latina que as atitudes homofóbicas foram positivamente associadas ao sexo masculino e à prática religiosa, em particular cristãos não-católicos.

Outro motivo de rejeição aparece quando os alunos dizem que aceitam os homossexuais, desde que "não lhes façam mal". Esse mesmo tipo de discurso não ocorreu em relação a heterossexuais. Em contraposição, alguns afirmaram que a troca de carícias em público entre pessoas do mesmo sexo é uma atitude corajosa, pois se expondo estão mostrando o que eles são de verdade, sem se oprimir por causa dos outros. Outra forma de preconceito debatida entre os nossos interlocutores foi a constatação de que os homossexuais podem influenciar as crianças a se tornaram homossexuais. A discriminação também foi manifestada por eles por exclusão, xingamentos e brincadeiras de dizer que precisa "virar homem", entre outras.

Aspecto relevante a ser destacado é o aparente maior acolhimento de casais de mulheres do que de homens. Por este motivo elas se expõem mais no colégio que os rapazes. Segundo os relatos, é muito mais fácil acontecer um beijo em público entre duas mulheres do que entre dois homens. Constatamos nas narrativas que as atitudes explicitamente preconceituosas, quando existem na escola, são mais frequentes em relação ao homossexual masculino. Razão pela qual a homossexualidade feminina, apesar de muito mais visível na escola do que a masculina, foi secundária na fala dos alunos. Estes, quando perguntados a respeito da discriminação, referiram-se majoritariamente aos rapazes gays.

A homossexualidade feminina, por outro lado, é encarada por alguns como algo excitante, como um fetiche.

"Acho mais legal ver duas mulheres se beijando do que dois homens" (aluno, G3).

A homofobia menos intensa contra as mulheres, percebida por nossos interlocutores, vai ao encontro dos estudos de Leonel 25 sobre lesbofobia. A autora afirma que as lésbicas parecem sofrer menos discriminação do que os gays e aponta como hipótese para essa diferença a invisibilidade histórica das mulheres nos espaços públicos com a consequente menor exposição na mídia, nas ruas e nos ambientes de trabalho, acentuadas pela maior aceitação social de manifestações de afeto entre mulheres. Assim, supõe-se que se as mulheres homossexuais são de fato menos percebidas pelas pessoas ao redor, serão, consequentemente, menos discriminadas.

Alguns jovens afirmaram que muitas mulheres buscam se relacionar com outras mulheres por terem sofrido violência de homens com quem se relacionaram. Esta afirmação segue o mesmo sentido daquela em que "mulher que vira lésbica é porque não conheceu homem de verdade", admitida por $31 \% \mathrm{da}$ população do estudo de Leonel 25 (p. 91). Estas duas concepções socialmente disseminadas e a fetichização das lésbicas exemplificam a intrínseca ligação entre machismo e lesbofobia, em que a mulher deve subjugar sua sexualidade à masculina e o desejo por outra mulher se daria apenas na impossibilidade de se relacionar com um homem.

A maior exposição pública de carinhos entre mulheres está de acordo com o estereótipo do gênero feminino 26 . Ser terna, delicada e carinhosa faz parte daquilo esperado do feminino, independente da orientação sexual. Por outro lado, no processo de socialização dos homens, a masculinidade se efetua em constante oposição à feminilidade. Para ser macho tem que ser agressivo, forte, competitivo e heterossexual 5 . 


\section{A escola e a diversidade sexual}

As narrativas sobre as atitudes dos educadores frente à diversidade sexual foram variadas. Uma parcela dos estudantes relata que não há discriminação por parte dos coordenadores pedagógicos e professores. Outros declararam que algumas instituições impõem constrangimentos aos alunos que não são heterossexuais.

A diversidade sexual não se mostrou um tema presente nas atividades escolares, pois nenhum de nossos interlocutores referiu iniciativas da escola neste sentido. As atitudes discriminatórias explícitas advindas de professores e/ou das coordenações dos estabelecimentos escolares foram pouco descritas, contudo, alguns alunos expressaram a opinião de que todas as escolas são homofóbicas. Houve relatos de professores que se recusam a chamar a aluna transexual pelo nome social e que fazem piadinhas com homossexuais.

Em todos os grupos, os poucos empreendimentos discriminatórios da escola citados por nossos interlocutores foram a proibição de alunas namoradas entrarem juntas no banheiro e a repressão aos relacionamentos amorosos em público de alunos do mesmo sexo dentro ou nos arredores da escola, quando uniformizados. O mesmo não acontece se o casal for heterossexual.

"Aí, um casal hétero, se beijando no corredor, a coordenação passa, não faz nada... Mas, se tiver dois homossexuais, eles vão reclamar" (aluna, G7).

“Uma aluna não pode ir no banheiro com a outra porque a coordenação simplesmente proibiu..." (aluna, G9).

De acordo com Junqueira 6, os currículos escolares são artefatos políticos e de produção cultural, que podem (re)produzir as normas de gênero sociais, a heteronormatividade, afetando não só aos que fogem à norma. Portanto, a escola deve desenvolver ações para além daquelas voltadas ao desempenho acadêmico, pois é um espaço privilegiado que, dependendo de sua atuação, pode corroborar ou não para a cristalização de percepções preconceituosas em relação às condutas que fogem do padrão heteronormativo da sociedade.

As primeiras experiências com educação sexual na escola na década de 1960 tinham caráter higienista. A partir dos anos 1970, com as demandas do movimento feminista, esta situação começou a se modificar, mas somente nos anos 1990 passaram a ter propostas educativas mais efetivas, motivadas pela aids e pelo aumento da gravidez na adolescência. Em 1995, como resposta aos movimentos sociais e à crítica aos programas educativos da forma como eram propostos, o governo incluiu a sexualidade nos Parâmetros Curriculares Nacionais como tema transversal, articulado a outros temas como ética, saúde, gênero, ecologia e pluralidade cultural 27.

O tema sexualidade deveria ser trabalhado de forma contínua, sistemática e integrada ao trabalho educativo da escola, o que não é feito nas escolas estudadas, tendo sido até sugerido por alguns participantes a realização de outros grupos para dar continuidade ao debate sobre o tema e também o convite à participação do diretor da escola na atividade. Percebe-se, portanto, que passadas duas décadas, o tema diversidade sexual ainda não está presente nos currículos do Ensino Médio 28.

A partir de 2001, com a criação do Conselho Nacional de Combate à Discriminação, as minorias sexuais foram incluídas na pauta dos gestores de políticas públicas e, em 2004, surgiu o Programa Brasil sem Homofobia elaborado pela Secretaria Especial de Direitos Humanos. O Projeto Escola Sem Homofobia, articulado com o programa Brasil Sem Homofobia, criou material educativo, com o apoio de ONGs, que abordava de modo sistemático a homofobia. No entanto, isso foi considerado uma ofensa às famílias brasileiras, e por pressão política foi vetada sua utilização ${ }^{29}$. Assim, perde-se a oportunidade de apoiar os estudantes em inquietações relacionadas às experimentações sexuais comuns entre adolescentes, e também de capacitar educadores sobre o tema, pois, conforme exteriorizado pelos participantes deste estudo, eles são de outra geração, com outros valores, tendo mais dificuldade de aceitar diferentes escolhas afetivas e sexuais.

Alguns autores recomendam a implantação de políticas e programas no sentido de melhorar o ambiente escolar, incluindo temas como diversidade e orientação sexual, combate ao bullying LGBTfóbico, bem como programas de aliança entre estudantes gays e heterossexuais. Afirmam ainda que, quanto mais seguros os adolescentes se sentem no ambiente educacional, maior a probabilidade de redução de riscos à sua saúde mental e evasão escolar 30 . Os participantes deste estudo exteriorizaram preocupação com aqueles que sofrem bullying LGBTfóbico e não têm qualquer proteção por parte da escola. A omissão e o silêncio sobre o tema diversidade é uma forma sutil de concordância com o 
sistema heteronormativo da sociedade. Para combater a homofobia é essencial incluir a diversidade sexual como tema educacional 31. De longa data a educadora Louro 32 destaca que a invisibilização de estudantes homo e transexuais contribui para a marginalização destes. O fato de a escola ignorar os homossexuais autoriza os pares a insultá-los e a fazer brincadeiras ofensivas. E, de acordo com Seffner 33, além das propostas educativas sobre diversidade sexual, é necessário que se discuta na escola a heteronormatividade, para explicar sua origem e os dispositivos de ordem disciplinar e de controle sobre o corpo dos indivíduos e sobre as populações 11 .

As diretrizes de atenção à saúde do adolescente do Ministério da Saúde preconizam ações de promoção de saúde no contexto escolar, que incluem temas estruturantes como padrões de conduta e valores sociais historicamente construídos e, entre outras questões, aquelas que influenciam nas diferenças de expectativas e de papéis sociais que repercutem no crescimento e desenvolvimento saudáveis deste grupo populacional. A escola é o meio social que concentra grande número de jovens, portanto, tem forte influência em sua saúde. Daí a importância de se pensar ações de saúde nestes espaços. Dentro dessa perspectiva foi instituído, em 2006, o Projeto Saúde e Prevenção nas Escolas (SPE. http://portal.mec.gov.br/projeto-saude-e-prevencao-nas-escolas-spe), uma parceria do Ministério da Educação com o Ministério da Saúde, com vistas a atingir o público específico de adolescentes escolares, sendo uma das suas ações principais voltadas para a promoção da saúde sexual e reprodutiva de adolescentes. Essa política governamental, contudo, foi substituída em 2007 pelo Programa Saúde na Escola (PSE), que encampou suas ações dentro de um contexto maior que inclui outras faixas etárias, sem dar prioridade às questões relacionadas à sexualidade 34 .

Várias são as dificuldades de implementação de proposta pedagógica sobre o tema sexualidade, entre elas a falta de formação específica dos educadores que leva a intervenções em sala de aula baseadas nos seus próprios valores. De acordo com Nardi \& Quartiero 27, muitas vezes as intervenções acontecem para atender problemas que surgem na escola. Ao atuar de forma pontual e remeter a intervenção à esfera individual, a escola reforça a cultura homofóbica e sexista e não promove o questionamento do caráter discriminatório dos atos violentos, dos insultos, pois estas práticas estão naturalizadas. O educador acaba sendo também um agente de normalização dos comportamentos de ordem sexual, vistos por muitos como de foro íntimo e individuais e não como uma questão de direitos. A escola age adestrando os alunos para controlar os seus sentidos e sexualidade, a fim de fazer funcionar o ambiente escolar isento de posicionamentos ideológicos 11 . Por outro lado, o que se observa é que mesmo quando as escolas não tratam especificamente do tema sexualidade, as práticas normativas relacionadas ao comportamento sexual e de gênero estão lá presentes e ativas no cotidiano escolar. Portanto, a capacitação de educadores sobre o tema sexualidade e diversidade sexual é de grande importância não só para que estejam preparados para lidar com as frequentes situações que perpassam a vida sexual dos estudantes e inevitavelmente atravessam a escola, mas também para própria reflexão sobre suas convicções e preconceitos que afetam suas práticas educacionais. E os programas educativos devem levar em conta especificidades contextuais e históricas relativas à heteronormatividade e à diversidade sexual.

Apesar da aparente não discriminação por parte dos professores, nossos interlocutores ponderaram que ela depende da escola. Algumas são mais abertas e aceitam mudanças com mais facilidade, a exemplo do Colégio Pedro II, que permite o uso de saias pelos estudantes do sexo masculino, o que jamais ocorreria se fosse no Colégio Militar. Foi argumentado por eles também que, pelo fato de os professores serem de outras gerações, estes são mais preconceituosos.

"Eu acho que a geração deles teve uma visão desse mundo homossexual não tão aberta. Então, eles não têm essa facilidade que a gente tem de aceitar as coisas" (aluna, G7).

"Os valores, eles receberam valores completamente diferentes do que a gente tá recebendo agora. Não tinha tanto explícito homossexual se beijando no meio" (aluna, G7).

Quanto à lida com a pessoas trans, os alunos comentam que certamente o estudante que se vestisse com uniforme designado às mulheres sofreria retaliações da direção. Tornou-se nítida nas narrativas a omissão dos educadores nos temas relacionados à diversidade sexual, evidenciada por pedidos dos próprios alunos para que a equipe da pesquisa voltasse à escola para realizar outras atividades relativas à temática e também pela não repressão ao bullying LGBTfóbico contra os estudantes não heterossexuais.

Em estudo de Cassal \& Zucco 35 sobre a percepção de docentes de escolas públicas e particulares da região metropolitana do Rio de Janeiro, os pesquisadores constataram que a escola fala sobre 
sexualidade a partir da heterossexualidade, com os professores esperando dos alunos um comportamento "adequado" ao sexo biológico deles. Identidades não enquadradas na heteronorma foram consideradas como fora da realidade escolar.

"Eles... tipo, excluem a pessoa, das coisas, ficam fazendo bullying. Porque a pessoa pode fingir que não é nada, sabe? Mas pra ela é difícil, ela vai chorar, ela vai ficar triste... E os professores aceitam. Pelo menos eu nunca vi nenhum tipo de repressão...” (aluna, G1).

Essa aceitação por parte dos professores sustenta e fortalece a hierarquia do masculino sobre o feminino. Quando os alunos foram questionados sobre a quem recorreriam para discutir conteúdos sobre sexualidade - em perspectiva ampliada incluindo namoro, violência, gênero e diversidade sexual - o professor foi rejeitado como opção, explicitando o distanciamento entre escola e corpo discente neste campo. Houve quem dissesse que seria importante o diretor da escola estar participando do grupo focal.

Méndez-Tapia ${ }^{36}$, em estudo crítico sobre homofobia, educação e diversidade sexual, destaca que os códigos e regulamentações de gênero que existem na sociedade condicionam tanto os espaços de educação formal como outros lugares de aprendizagem informal, os quais modelam os tipos de socialização que fortalecem o regime heterossexual e as autoridades simbólicas e formais em matéria de moralidade, que não só definem os comportamentos masculinos e femininos saudáveis como decretam o que é esperado e legítimo para a conduta dos estudantes. Os códigos de gênero operam como uma política de verdade no interior dos espaços educativos ao estabelecer as bases normativas de prescrição e de sanção que deificam as atitudes, os comportamentos e as imagens segundo modelos pré-estabelecidos de masculinidade e feminilidade. Como diz Preciado 37, filósofo espanhol, desde cedo a sociedade usa instrumentos pedagógicos que não são facilmente percebidos como tal, que vigiam e policiam os bebês para transformá-los em crianças heterossexuais.

\section{Considerações finais}

Nosso estudo, limitado ao universo dos estudantes do Ensino Médio e a grupos naturais de indivíduos que se conheciam, verificou que a LGBTfobia é plenamente manifesta nos ambientes escolares e invisível aos olhos da escola, na percepção dos nossos interlocutores. Isso sugere que os programas e políticas públicas de educação e de saúde existentes não estão garantindo os direitos sexuais desta população, bem como sua proteção, pois se trata de indivíduos em desenvolvimento. Para a vivência da sexualidade de forma livre, segura e saudável é necessário oferecer aos seres em desenvolvimento condições adequadas para a manifestação de seus desejos e inquietações e o ambiente escolar é o mais indicado para isso. Contudo, vale destacar que há maior aceitação dos adolescentes LGBTs, pois os estudantes estão mais abertos a mudanças, igualmente nas escolas públicas e privadas, mesmo num ambiente escolar heteronormatizador e discriminatório, comum a ambos os tipos de estabelecimentos escolares.

No momento atual, além da baixa efetividade das políticas neste campo, evidencia-se movimentos contrários a ela, a exemplo da retirada do termo gênero e orientação sexual do texto do Plano Nacional de Educação, aprovado em 2014, provocada pela bancada religiosa do Congresso Nacional brasileiro. Outro movimento digno de nota é o Escola Sem Partido - Projeto de Lei no 193/2016 (https:// www25.senado.leg.br/web/atividade/materias/-/materia/125666), que representa uma grave ameaça a uma educação emancipadora e garantidora de direitos, cuja ideologia, ao contrário do que prega quando diz que visa à neutralidade, pretende impedir debates e práticas pedagógicas relacionadas, entre outras, a questões sobre gênero e sexualidade. 


\section{Colaboradores}

Todos os autores contribuíram igualmente na escrita e na revisão final do texto.

\section{Informações adicionais}

ORCID: Thenessi Freitas Matta (0000-0001-82471671); Stella Regina Taquette (0000-0001-73883025); Luciana Maria Borges da Matta Souza (00000002-7053-5903); Claudia Leite de Moraes (00000002-3223-1634).

\section{Referências}

1. Worfld Health Organization. Young people's health - challenge for society. Geneva: World Health Organization; 1986.

2. Heilborn ML, Aquino EML, Bozon M, Knauth DR. O aprendizado da sexualidade: reprodução e trajetórias sociais de jovens brasileiros. Rio de Janeiro: Garamond/Editora Fiocruz; 2006.

3. Taquette SR, Rodrigues AO. Experiências homossexuais de adolescentes: considerações para o atendimento em saúde. Interface (Botucatu) 2015 ; 19:1181-91.

4. Junqueira RD. A pedagogia do armário: heterossexismo e vigilância de gênero no cotidiano escolar. Revista Educação On-line PUC-Rio 2012; (10):64-83.

5. Borillo D. Homofobia - história crítica de um preconceito. Belo Horizonte: Autêntica; 2010.

6. Junqueira RD. Currículo heteronormativo e cotidiano escolar homofóbico. Espaço do Currículo 2010; 2:208-30.

7. Blais M, Gervais J, Hébert M. Homofobia internalizada como mediador parcial do bullying homofóbico e autoestima entre jovens de minorias sexuais em Quebec (Canadá). Ciênc Saúde Colet 2014; 13:727-35.

8. Gibbs JJ, Rice E. The social context of depression symptomology in sexual minority male youth: determinants of depression in sample of Grindr users. J Homosex 2016; 63:278-99.

9. Shields JP, Whitaker K, Glassman J, Franks HM, Howard K. Impact of victimization on risk of suicide among lesbian, gay, and bisexual high school students in San Francisco. J Adolesc Health 2012; 50:418-20.

10. Teixeira-Filho FS, Rondini CA. Ideações e tentativas de suicídio em adolescentes com práticas sexuais hetero e homoeróticas. Saúde Soc 2012; 21:651-67.

11. Foucault M. História da sexualidade I - a vontade de saber. 13a Ed. Rio de Janeiro: Graal; 1999.

12. Asinelli-Luz A, Cunha JM. Percepções sobre a discriminação homofóbica entre concluintes do ensino médio no Brasil entre 2004 e 2008. Educ Rev 2011; (39):87-102.

\section{Agradecimentos}

Agradecemos a participação, durante o desenvolvimento da pesquisa, dos bolsistas de iniciação científica da Universidade do Estado do Rio de Janeiro (UERJ) Mariana Carneiro e Luca Zingali Meira, da professora de enfermagem da UERJ Simoni Furtado Costa e da assistente social Juliane Escascela.

13. Minayo M. O desafio do conhecimento: pesquisa qualitativa em saúde. São Paulo: Hucitec Editora; 2014.

14. Costa AP, Loureiro MJ, Reis LP, Neri de Souza F. Análise de interações focada na colaboração e cooperação do modelo 4C. Revista Lusófona de Educação 2015; 29:19-39.

15. Denzin NK, Lincoln YS. The Sage handbook of qualitative research. Thousand Oaks: Sage Publications; 2018.

16. Departamento de Apoio à Gestão Participativa, Secretaria de Gestão Estratégica e Participativa, Ministério da Saúde. Transexualidade e travestilidade na saúde. v. 1. Brasília: Ministério da Saúde; 2015.

17. Venturi G, Bokany V. Diversidade sexual e homofobia no Brasil. v. 1. São Paulo: Editora Fundação Perseu Abramo; 2011.

18. Barbero MS. Hacerse hombre en el aula: masculinidad, homofobia y acoso escolar. Cadernos Pagu 2017; (50):e175014.

19. Rondini CA, Teixeira Filho FS, Toledo LG. Concepções homofóbicas de estudantes do ensino médio. Psicol USP 2017; 28:57-71.

20. Magnavita AD. Identidade gay e os preconceitos que cerceiam a tolerância. Revista Filosofia 2008; $14-23$

21. Souza JM, Silva JP, Faro A. Bullying e homofobia: aproximações teóricas e empíricas. Psicol Esc Educ 2015; 19:289-98.

22. Albuquerque PP, Williams LCA. Homofobia na escola: relatos de universitários sobre as piores experiências. Temas Psicol (Online) 2015; 23:663-76

23. Rull MAP, Leyva AH, Ortiz FM, Mendoza EP, Rodríguez PP-P, Rosado SS. Homofobia en universidades de la Ciudad de México. Revista Intercontinental de Psicología y Educación 2013; 15:93-114.

24. Chaux E, León M. Homophobic attitudes and associated factors among adolescents: a comparison of six Latin American countries. J Homosex 2016; 63:1253-76. 
25. Leonel V. Lesbofobia. In: Venturi G, Bokany V, organizadores. Diversidade sexual e homofobia no Brasil. v. 1. São Paulo: Editora Fundação Perseu Abramo; 2011. p. 89-96.

26. Palma YA, Levandowski DC. Vivências pessoais e familiares de homossexuais femininas. Psicol Estud 2008; 13:771-9.

27. Nardi HC, Quartiero E. Educando para la diversidad: desafiando la moral sexual y construyendo estrategias de combate a la discriminación en el cotidiano escolar. Sex Salud Soc (Rio J.) 2012; (11):59-87.

28. Pereira GR, Bahia AGMF. Direito fundamental à educação, diversidade e homofobia na escola: desafios à construção de um ambiente de aprendizado livre, plural e democrático. Educ Rev 2011; (39):51-71.

29. Garcia PS, Bizzo N. O processo de elaboração dos planos municipais de educação na Região do Grande ABC. Educação \& Realidade 2018; 43:337-62.

30. Saewyc EM, Konishi C, Rose HA, Homma Y. School-based strategies to reduce suicidal ideation, suicide attempts, and discrimination among sexual minority and heterosexual adolescents in Western Canada. Int J Child Youth Family Stud 2014; 5:89-112.
31. Altmann H. Diversidade sexual e educação: desafios para a formação docente. Sex Salud Soc (Rio J.) 2013; (13):69-82.

32. Louro GL. Gênero, sexualidade e educação uma perspectiva pós-estruturalista. 6a Ed. Petrópolis: Vozes Editora; 1997.

33. Seffner F. Sigam-me os bons: apuros e aflições nos enfrentamentos ao regime da heteronormatividade no espaço escolar. Educação e Pesquisa 2013; 39:145-59.

34. Departamento de Atenção Básica, Secretaria de Atenção à Saúde, Ministério da Saúde. Saúde na escola. Brasília: Ministério da Saúde; 2009. (Série B. Textos Básicos de Saúde) (Cadernos de Atenção Básica, 24).

35. Cassal LCB, Zucco LP. Diversidade sexual e gênero na escola: uma experiência de extensão no Rio de Janeiro. Extensão em Foco 2010; (5):15-23.

36. Méndez-Tapia M. Reflexiones críticas sobre homofobia, educación y diversidad sexual. Educação \& Realidade 2017; 42:673-86.

37. Preciado PB. ¿Quién defiende al niñx queer? In: Preciado PB, editor. Terror anal y manifiestos recientes. Buenos Aires: La Isla de La Luna; 2013. p. 69-76. 
Abstract

LGBTphobia constitutes a context of vulnerability to the health of individuals whose sexuality is diverse from the heteronormative pattern, named sexual minorities, especially in adolescence, a period of sexual identities definition. The aim of this study was to analyze how did high school students perceive their peers of sexual minorities and how they understand the school's and educators' attitude regarding sexual diversity. The research used the qualitative method, with 13 focal groups comprising 132 students of both sexes, from public and private schools in the Municipality of Rio de Janeiro, Brazil. The data analysis was performed with the support of webQDA software in a comprehensive basis approach. Data were classified in two categories. In the first category, the students and sexual diversity, the participants perceived sexual diversity as normal because it is common and often present in their age. However, they confirmed homophobic attitudes against those whose gender behavior is not in accordance with what is expected for their biological sex. In the second category, the school and sexual diversity, the students recognized the adoption of discriminatory measures against same-sex couples by the school coordination and the absence of the theme of sexual diversity in educational activities. The outcomes indicate that sexual education policies are not sufficient to guarantee the human rights of sexual minorities and this represents greater health vulnerability of this population strata.

Homophobia; Sexuality; Adolescent; Students; Qualitative Research

\section{Resumen}

La LGBTfobia se conforma como un contexto de vulnerabilidad para la salud de las personas cuya sexualidad es diferente respecto al patrón heteronormativo, denominadas minorías sexuales, principalmente en la adolescencia, período de definición de las identidades sexuales. El objetivo de este estudio fue analizar cómo estudiantes de enseñanza media perciben a sus compañeros de minorías sexuales, y cómo entienden la actitud de la escuela, así como la de los educadores, frente a la diversidad sexual. El método utilizado fue cualitativo, mediante 13 grupos focales con 132 estudiantes de ambos sexos, de escuelas públicas y privadas del Municipio de Río de Janeiro, Brasil. El análisis de los datos se realizó con el apoyo del software webQDA, en un abordaje de base comprensivo y clasificados en dos categorías. En la primera, denominada estudiantes y diversidad sexual, los participantes perciben la diversidad sexual como normal, puesto que es común y se presenta frecuentemente en su edad. No obstante, confirmaron actitudes homofóbicas contra quienes cuyo comportamiento de género no está de acuerdo con lo esperado para su sexo biológico. En la segunda categoría, escuela y diversidad sexual, los estudiantes reconocen la adopción de medidas discriminatorias contra parejas homoafectivas por parte de la coordinación escolar y la ausencia del tema diversidad sexual en las actividades educativas. Los resultados indican que las políticas de educación sexual son insuficientes para la garantía de los derechos humanos de las minorías sexuales, lo que representa una mayor vulnerabilidad para la salud de ese estrato poblacional.

Homofobia; Sexualidad; Adolescente; Estudiantes; Invetigación Cualitativa
Recebido em 25/Nov/2020

Versão final reapresentada em 08/Fev/2021

Aprovado em 19/Mar/2021 